\title{
The Effectiveness of Trigger Point Injection Plus Kinesio Taping in Myofascial Pain Syndrome: a Randomized, Sham-Controlled Clinical Trial
}

\author{
E. Yılmaz
}

Department of Physical Therapy and Rehabilitation, Kocaeli Government Hospital, Kocaeli, Turkey

\author{
CORRESPONDING AUTHOR:

\section{Ebru Yılmaz} \\ Department of Physical Therapy and \\ Rehabilitation \\ Kocaeli Government Hospital \\ Gunes Street 41300 \\ Kocaeli, Turkey \\ E-mail: dr.ozcanebru@gmail.com
}

\section{DOI:}

10.32098/mltj.02.2021.07

LEVEL OF EVIDENCE: 1B

\begin{abstract}
SUMMARY
Objective. Although the trigger point injection (TPI) is the most widely used treatment method in myofascial pain syndrome (MPS), other treatment methods have also been proven to be influential. Even if a certain level of pain relief is achieved after the TPI, this effect persists for a short time and a few treatment sessions are generally required. Hence, a multidisciplinary approach to treatment seems to be most useful. Therefore, this study aimed to evaluate the efficacy of the combination of TPI with kinesio taping (KT) on the trapezius muscle in the treatment of MPS.

Methods. 50 patients with MPS were randomly separated into two groups (25 patients per group): Group 1: TPI plus KT; Group 2: TPI plus sham KT. Visual analog scale (VAS) and neck disability index (NDI) were recorded at baseline and 1, 3 months post-treatment.

Results. The mean age of patients was $42.5 \pm 13.89$ and $43.8 \pm 12.23$ years in Group 1 and Group 2, respectively. In Group 1, pre- and post-treatment (at 1 and 3 months) VAS/NDI scores were $8.0 \pm 0.45 / 40.96 \pm 1.27,0.08 \pm 0.28 / 7.51 \pm 2.55$, and $0.44 \pm$ $0.51 / 8.96 \pm 3.27$, respectively. In Group 2, pre- and post-treatment (at 1 and 3 months) VAS/NDI scores were $8.0 \pm 0.54 / 41.21 \pm 1.54,0.25 \pm 0.44 / 8.35 \pm 2.75$, and $2.33 \pm$ $1.44 / 13.98 \pm 5.63$, respectively. VAS and NDI scores at 3 months were significantly lower in Group 1 versus Group $2(\mathrm{p}<0.05)$.

Conclusions. The complex pathology with underlying peripheral and central neural mechanisms of MPS might conduce to the difficulties within the treatment of MPS, especially within the chronic period. The combined therapy appears to generate a more influential outcome for a long run than monotherapy in alleviating pain and reforming functional amelioration in the management of MPS.
\end{abstract}

\section{KEY WORDS}

Myofascial pain syndrome; trigger point injection; kinesio taping.

\section{INTRODUCTION}

Myofascial pain syndrome (MPS) is a musculoskeletal pain condition defined by local and referred pain sensed as deep and aching and with the existence of myofascial trigger points in skeletal muscles or fascia in any part of the body. A myofascial trigger point $(\mathrm{MTrP})$ is a hyperirritable spot in skeletal muscle or muscle's fascia that is linked by a hypersensitive palpable nodule in a taut band (1).

The major symptoms of MPS are tenderness to palpation with referred pain to the other muscles of the body or joints, limited range of motion and hassle to relax or fully length- en the muscle, longer-lasting muscle pain, weakness and stiffness, sleep disturbance, and autonomic phenomena such as vasomotor and temperature disturbance, sweating, lacrimation, dermal flushing, coryza, salivation, pilomotor erection, proprioceptive disorder. Cervical myofascial pain may be linked by neuro-otologic symptoms such as dizziness, imbalance, and tinnitus. It might attend with a sensory ingredient of paresthesias or dysesthesias. Additionally, it could simulate other pains such as radicular pain or visceral pain (1).

Myofascial pain is an important health cause influencing as much as $85 \%$ of the general population sometime in their 
lifetime while the estimated overall prevalence is $\sim 46 \%$. Common etiologies of MPS could be from exposure to cumulative and repetitive strain, spine pathology, postural dysfunction, and physical deconditioning, and direct or indirect trauma. The affected muscles are frequently the muscles in the neck, shoulders, and pelvic girdle such as the trapezius, sternocleidomastoid, levator scapulae, scalene, infraspinatus, quadratus lumborum, and gastrocnemius, which are used to preserve body posture. The trapezius is the muscle in which MTrPs consist frequently. MTrPs in trapezius muscle might produce chronic upper-quarter pain, neck pain, migraine, headache, tinnitus, temporomandibular joint pain, eye symptoms, torticollis, or shoulder pain $(1,2)$.

The natural course of MPS is spontaneous recovery, persistence without progression, and additional $\mathrm{TrP}$ and chronicity. The prime aims of the management are alleviating pain with the inactivation of $\mathrm{TrPs}$, fixing a range of motion (ROM) of the joints, prevention of recurrence, and extinguishing predisposing factors (mechanical factors such as poor posture, structural abnormality, systemic factors such as vitamin deficiency, hypothyroidism, chronic infection/infestation and psychological factors such as psychosomatic diseases, depression and secondary gain) for MTrPs. The major governance choices contain management of predisposing factors, patient education, medications by analgesics, myorelaxants and antidepressants, stretch and spray, therapeutic massage, ischemic compression, biofeedback, hot pack, transcutaneous electrical nerve stimulation (TENS), interferential (IFA) current, ultrasound (US), extracorporeal shock wave therapy (ESWT), low energy light amplification by stimulated emission of radiation (LASER), trigger point injections (TPIs, with local anesthetics (LAs), corticosteroids, nonsteroidal antiinflammatory drug, saline or botulinum toxin), dry needling and acupuncture (3). Although there are wide variations in application models, there is no obvious consensus on when and how to use these interventions. Even though TPI is the most widely used treatment method, other treatment methods have also been proven to be influential. In clinical practice, even if a certain level of pain relief is achieved after TPI, this effect persists for a short time and a few treatment sessions are generally required. Hence, a multidisciplinary approach to treatment seems to be most useful $(1,4)$. Moreover, a few studies are supporting the efficacy of KT for MPS in the trapezius muscle (5). Hence, this study aimed to evaluate the effectiveness of the combination of TPI with KT on the trapezius muscle in the management of MPS.

\section{MATERIALS AND METHODS}

The randomized sham-controlled clinical trial was directed at the patients with MPS in an outpatient ambulatory setting who applied to Kocaeli Government Hospital, Kocaeli, Turkey, between March 2019 and May 2019. The study protocol was approved by the Ethical Committee of Kocaeli University (Trial Registration: KU GOKAEK 2018/197). Written informed consent was obtained from all patients.

\section{Participants}

A total of 50 patients ( 32 female, 18 male) were contained in this trial. The diagnosis of MPS was made in accordance with the diagnostic criteria of Travell and Simon. These criteria include five major and three minor criteria. Major criteria are: 1) regional pain complaint in the neck, 2) pain complaint or altered sensation in the expected distribution of referred pain from a myofascial trigger point, 3) taut band palpable in accessible muscle, 4) excruciating spot tenderness at one point along the length of the taut band and 5) some degree of restricted range of motion when measurable. Minor criteria are: 1) reproduction of clinical pain complaint, or altered sensation, by pressure on the tender spot, 2) eliciation of a local twitch response by transverse snapping palpation at the tender spot or by needle insertion into the tender spot in the taut band and 3) pain alleviated by elongating (streching) the muscle or by injecting the tender spot (trigger point) (1). Inclusion criteria were the patients who had an active MTrP in the trapezius region and taut palpable band and failed to respond to previous medication, age between 20 and 65 years, and neck and/or upper back pain in the normal range with symptom duration of at least one month. Exclusion criteria were the patients diagnosed with fibromyalgia, history of pregnancy, systemic diseases such as hypertension, diabetes mellitus and rheumatic illness or bleeding disorders, trauma and neck surgery, the patients with cervical disc lesions and radiculopathy or myelopathy, using the anticoagulant medication, a history of allergy to LAs and previous history of TPI within the preceding six months (table I). All patients were randomly separated into two groups ( 25 patients per group) through random allocation using a computer-generated random number: Group 1: TPI plus KT; Group 2: TPI plus sham KT. Firstly, Groups 1 and 2 were treated by TPI of $1 \mathrm{ml}$ of $20 \mathrm{mg}$ betamethasone dipropionate combined with $3 \mathrm{ml}$ of $2 \%$ lidocaine and $1 \mathrm{ml}$ of saline solution. In both groups, the point with a pinch between the thumb and index finger or between the index and middle finger was isolated. Then, a $\operatorname{TrP}$ was located and the overlying skin was sterilized with povidone-iodine solution. The needle was then inserted 1 to $2 \mathrm{~cm}$ away from the $\operatorname{TrP}$ and was advanced into the trigger point at an acute angle of 30 degrees to the skin.

The plunger was pulled before injection to guarantee that the needle is not in a blood vessel. A small amount $(1 \mathrm{ml})$ of 
Table I. Inclusion and exclusion criterias of the study.

\begin{tabular}{ll}
\hline Inclusion criterias & Exclusion criterias \\
\hline $\begin{array}{l}\text { The patients had an active myofascial trigger point in the } \\
\text { trapezius region and taut palpable band }\end{array}$ & $\begin{array}{l}\text { The patients with fibromyalgia, cervical disc lesions and radiculopathy or } \\
\text { myelopathy }\end{array}$ \\
\hline The neck and/or upper back pain in the normal range & $\begin{array}{l}\text { A history of pregnancy, trauma and neck surgery, systemic diseases } \\
\text { such as hypertension, diabetes mellitus and rheumatic illness or } \\
\text { bleeding disorders }\end{array}$ \\
\hline The presence of these symptoms for at least 1 month & A history of using the anticoagulant medication \\
\hline The patients who are between 20 and 65 years of age & A history of allergy to local anesthetics \\
\hline The patients failed to respond to previous medication & Previous history of trigger point injection within the preceding six months \\
\hline
\end{tabular}

the mixture was injected after the needle got into the TrP. Then, the needle was pulled to the level of subcutaneous tissues. It was redirected medially, laterally, inferiorly and superiorly. Needling and injection were repeated in all directions until the local twitch response no longer appeared or resisted muscle tautness (figure 1). Before the KT application, the skin was shaved if required, cleaned with alcohol, and dried. KT (VZN Tape Kinesiology) with a width of 10 $\mathrm{cm}$ and a thickness of $0.5 \mathrm{~mm}$ was used in both groups. In Group 1, four tapes were applied to a horizontal stripe across each other the most painful area with a maximum stretch on the injected trigger point (figure 2). In Group 2 , the same application (four tapes in a star shape) without tension was applied over the same point. KT was applied five times by intervals of 3 days for two weeks. All injections and applications were performed by the same physician (EY). The participants in both groups received home-based exercise programs including neck isometric exercises and trapezius muscle strengthening and stretching exercises. All patients were instructed about the exercises by physiotherapists and the first set of exercises were performed under

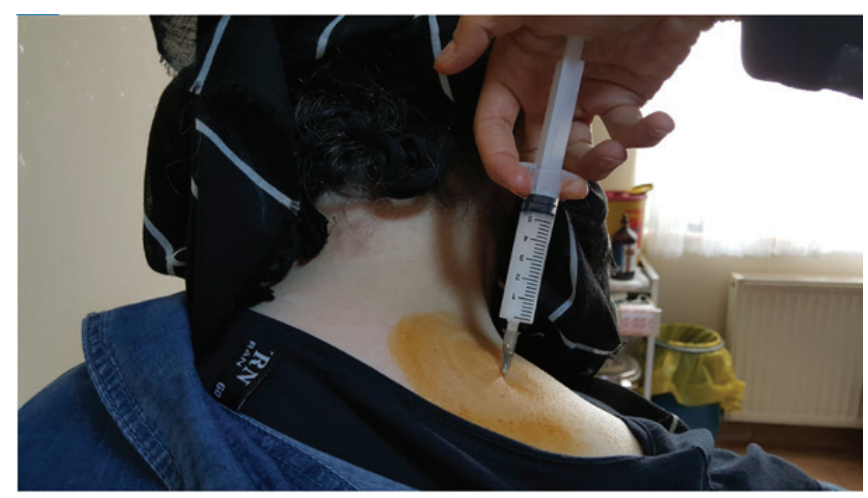

Figure 1. The injection technique used for trigger point. the supervision of clinical physiotherapists. These exercises were performed three times with 10 repetitions daily for two weeks. No adverse side effects were reported.

\section{Data extraction}

Data collected including age, sex, duration of symptoms, affected side of the trapezius muscle. The pain intensity using visual analog scale (VAS) and neck disability using neck disability index (NDI) were recorded at baseline and 1, 3 months post-treatment. VAS and NDI scores were recorded by a nurse. The nurse who collected the VAS and NDI scores was blinded to the assignment of groups.

\section{Statistical analysis}

Sample size and power calculation determined that 18 patients in each group were sufficient to power (power of $0.80, \alpha=0.05$, and $\beta=0.20$ ). The calculation of sample size was based on a mean difference of 2 points with 2.5 points standard deviation in the VAS according to previous data

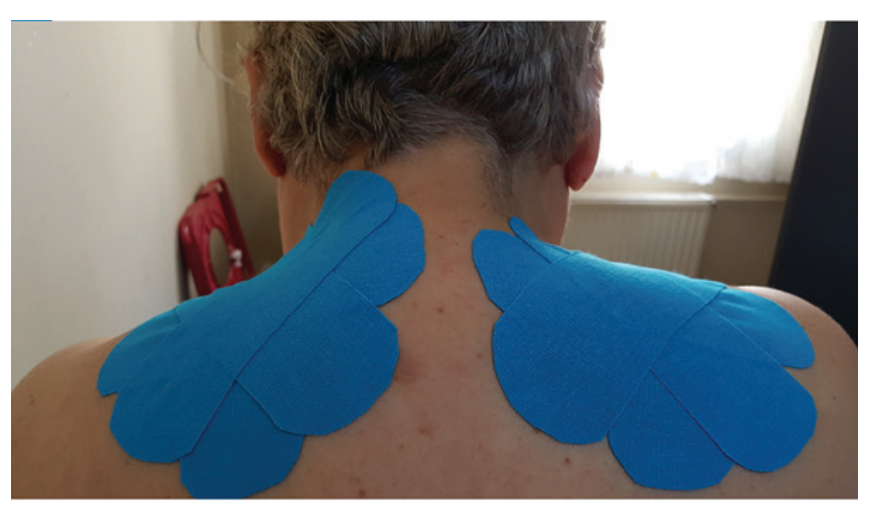

Figure 2. The technique used for kinesio taping. 
(20) using the PASS (power analysis and sample size) system. All statistical analyses were performed using IBM SPSS Statistics for Windows, Version 20.0 (IBM Corp., Armonk, NY, USA). For continuous data (age, symptom duration, VAS, and NDI score) descriptive statistics were expressed as mean \pm standard deviation (SD). For categorical data (sex, affected side of the trapezius muscle) were expressed as frequency and percentage. Relations among categorical variables were assessed by Chi-square analysis. Kolmogorov-Smirnov tests were used to determine whether or not the variables were normally distributed. Normal distributions of continuous variables were assessed by Student's t-test. Non-normally distributed metric variables were analyzed by Mann-Whitney U tests. Repeated non-normal VAS and NDI scores were compared using Friedman Two way ANOVA. P values $<0.05$ were considered statistically significant.

\section{RESULTS}

The demographic characteristics of patients including age, sex, duration of symptoms, affected side, and part of the trapezius muscle were presented in table II. The mean age of patients was $42.5 \pm 13.89$ and $43.8 \pm 12.23$ years in Group 1 and Group 2, respectively. Of all patients, 64\% $(\mathrm{n}=16)$ was female and 36\% ( $\mathrm{n}=9)$ was male in Group 1, 64\% ( $\mathrm{n}=16)$ is female and $36 \%(\mathrm{n}=9)$ was male in Group 2. The mean duration of symptoms is $17.36 \pm 17.59$ and $17.24 \pm 16.86$ months in Group 1 and Group 2, respectively. There was no statistically significant difference between groups regarding age, sex, symptom duration, and affected side ( $p>0.05)$.

In Group 1, pre- and post-treatment (at 1 and 3 months) VAS/NDI scores were $8.0 \pm 0.45 / 40.96 \pm 1.27,0.08 \pm$ $0.28 / 7.51 \pm 2.55$, and $0.44 \pm 0.51 / 8.96 \pm 3.27$, respectively. In Group 2, pre- and post-treatment (at 1 and 3 months) VAS/
NDI scores were $8.0 \pm 0.54 / 41.21 \pm 1.54,0.25 \pm 0.44 / 8.35 \pm$ 2.75 , and $2.33 \pm 1.44 / 13.98 \pm 5.63$, respectively. The change in VAS and NDI scores compared with the initial evaluation was shown in table III and table IV. VAS and NDI scores in 1 and 3 months significantly decreased in both groups compared to baseline $(\mathrm{p}<0.05)$. However, the VAS and NDI scores at 3 months were significantly lower in Group 1 versus Group $2(\mathrm{p}<0.05)$ (tables III and IV, figure $3 \mathbf{a}, \mathbf{b})$.

\section{DISCUSSION}

Recently, the most extensively admitted strategy for the management of MPS is to treat the underlying etiology. MTrPs might reactivate and MPS might sustain if the main cause is not warrantably treated. Different procedures can be utilized alone or in combination with varying degrees of success in the treatment of MPS. Moreover, the combined therapy rather than monotherapy is usually utilized to manage MPS in routine clinical practice $(1,6)$. In the regions of MTrPs, there is a muscle spasm due to an abberrant enhancement in the production and release of acetylcholine within the motor endplate at rest, resulting in reduced blood circulation because of the compression of nearby blood vessels. Additionally, nociceptors and peripheral nerve endings can be affected by several inflammatory factors, thus creating a vicious cycle of events and the autonomic symptoms of MPS owing to the activation of sympathetic fibers $(1,7)$. This study was hypothesized that the combination of TPI (by providing anti-nociceptive effect) and KT (by improving blood circulation) may produce better results. According to the results of this study, TPI plus KT group had significantly reduced pain and improved functional status compared to the TPI plus sham KT group.

Table II. Patients' characteristics of groups

\begin{tabular}{llll}
\hline Variables & $\begin{array}{l}\text { Group 1 }(\mathbf{n}=\mathbf{2 0}) \\
\text { Trigger point injection }(\mathrm{TPI}) \text { plus } \\
\text { kinesio taping }(\mathrm{KT})\end{array}$ & $\begin{array}{l}\text { Group 2 }(\mathbf{n}=\mathbf{2 0}) \\
\text { TPI plus sham KT }\end{array}$ & P value \\
\hline Age (years) & $42.5 \pm 13.89$ & $43.8 \pm 12.23$ & 0.53 \\
\hline $\begin{array}{l}\text { Sex } \\
\text { Female }\end{array}$ & $16(64 \%)$ & $16(64 \%)$ & 1.00 \\
Male & $9(36 \%)$ & $9(36 \%)$ & 0.46 \\
\hline $\begin{array}{l}\text { Symptom } \\
\text { duration (months) }\end{array}$ & $17.36 \pm 17.59$ & $17.24 \pm 16.86$ & \\
\hline $\begin{array}{l}\text { Affected side } \\
\text { Right }\end{array}$ & $8(32 \%)$ & $8(32 \%)$ \\
Left & $11(44 \%)$ & $10(40 \%)$ & 0.78 \\
Bilateral & $6(24 \%)$ & $7(28 \%)$ & \\
\hline
\end{tabular}

All values are expressed as mean \pm standard deviation (SD), number and percentage. $\mathrm{P}<0.05$, significant difference. 
Table III. Changes in VAS in before treatment and 1 and 3 months after treatment in Group 1 and 2.

\begin{tabular}{|c|c|c|c|}
\hline Variables & $\begin{array}{l}\text { Group } 1(n=20) \\
\text { Trigger point injection }(T P I) \text { plus } \\
\text { kinesio taping }(K T)\end{array}$ & $\begin{array}{l}\text { Group } 2(n=20) \\
\text { TPI plus sham KT }\end{array}$ & P value ${ }^{2}$ \\
\hline Before injection & $8.0 \pm 0.45$ & $8.0 \pm 0.54$ & $1.000^{2}$ \\
\hline 1 month after the injection & $0.08 \pm 0.28$ & $0.25 \pm 0.44$ & $0.289^{2}$ \\
\hline 3 months after the injection & $0.44 \pm 0.51$ & $2.33 \pm 1.44$ & $0.006^{2}$ \\
\hline $\mathrm{P}^{1}$ value & $<0.001^{\mathrm{a}, \mathrm{b}, \mathrm{c}}$ & $<0.001^{\mathrm{a}, \mathrm{b}}$ & \\
\hline
\end{tabular}

All values are expressed as mean \pm SD. $\mathrm{P}<0.05$, significant difference. ${ }^{1}:$ By Friedman Two way ANOVA. ${ }^{2}$ : By Mann-Whitney U-test. ${ }^{\text {a }}$ : there is differences between before injection and 1 month after injection. ${ }^{b}:$ there is differences between before injection and 3 months after injection. ${ }^{c}$ : there is differences between 1 month after injection and 3 months after injection.

Table IV. Changes in NDI in before treatment and 1 and 3 months after treatment in Group 1 and 2.

\begin{tabular}{llll}
\hline Variables & $\begin{array}{l}\text { Group 1 }(\mathbf{n}=\mathbf{2 0}) \\
\text { Trigger point injection }(\mathrm{TPI}) \text { plus } \\
\text { kinesio taping }(\mathrm{KT})\end{array}$ & $\begin{array}{l}\text { Group 2 }(\mathbf{n}=\mathbf{2 0}) \\
\text { TPI plus sham KT }\end{array}$ & P value $^{\mathbf{2}}$ \\
\hline Before injection & $40.96 \pm 1.27$ & $41.21 \pm 1.54$ & $0.883^{2}$ \\
\hline 1 months after the injection & $7.51 \pm 2.55$ & $8.35 \pm 2.75$ & $1.000^{2}$ \\
\hline 3 months after the injection & $8.96 \pm 3.27$ & $13.98 \pm 5.63$ & $0.002^{2}$ \\
\hline $\mathrm{P}^{1}$ value & $<0.001^{\mathrm{a}, \mathrm{b}, \mathrm{c}}$ & $<0.001^{\mathrm{a}, \mathrm{b}, \mathrm{c}}$ & \\
\hline
\end{tabular}

All values are expressed as mean $\pm \mathrm{SD} . \mathrm{P}<0.05$, significant difference. ${ }^{1}$ : By Friedman Two way ANOVA. ${ }^{2}$ : By Mann-Whitney U-test. ${ }^{\text {a: }}$ there is differences between before injection and 1 month after injection. ${ }^{b}$ : there is differences between before injection and 3 months after injection. ${ }^{c}$ : there is differences between 1 month after injection and 3 months after injection.

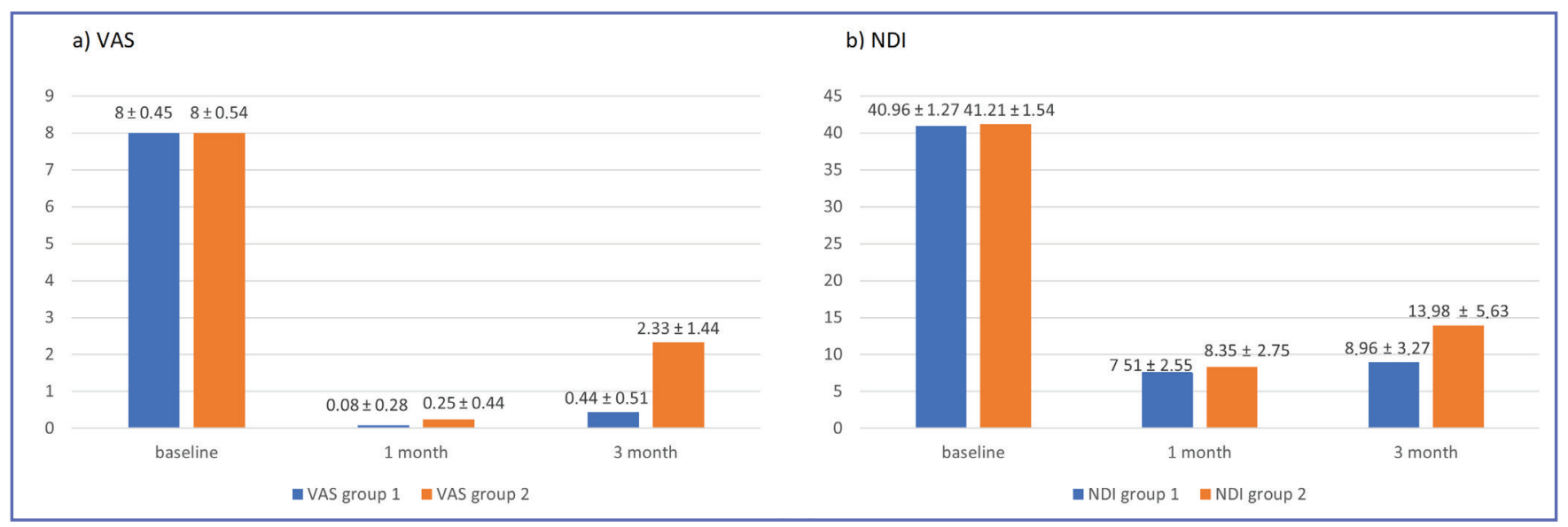

Figure 3. The median changes of VAS and NDI scores in TPI plus KT group (Group 1) and TPI plus sham KT group (Group 2).

TPIs are a widespread and efficacious therapy because of mechanical disruption by the needle and the ending of the dysfunctional activity in motor endplates. The effects of the applications of TPIs are: 1 ) to block nerve sensitizing substances, 2) to decrease hypersensitivity, 3) to release intracellular potassium depolarizing and disturbing nerve conduction, 4) to enhance circulation at the $\mathrm{TrP}$ via local vasodilation impact, 5) to block the passage of noxious inputs in the dorsal horn of spinal cord, 6) to activate the endogenous opioid system and 7) to break the vicious cycle of ischemia-pain-muscle spasm. TPI is an injection technique in which some materials are injected into the $\operatorname{TrP}$. LAs are the most widely injected materials. Outside of LAs, corticosteroids are commonly used for injection. 
TPI is utilized for patients with symptomatic active TrPs showing a twitch response to pressure and produce a pattern of referred pain $(3,6)$.

Even though corticosteroid injections in TrPs are still controversial owing to being little evidence to promote an underlying inflammatory pathophysiology, triamcinolone plus lidocaine has been found to induce a relatively higher rate of pain relief compared to lidocaine monotherapy (8). Besides, it is reasonable to do these injections with LAs considering the possible side effects of corticosteroids. In one study, it was shown that corticosteroids selectively block the transmission of nociceptive fibers, whereas local anesthetics can relax the muscles and break the cycle of pain and spasms $(9,10)$. Sonne et al. evaluated the effect of the injection of steroid and LA as therapy for low-back pain and found significant reductions in pain score and patients' self-assessments (11).

Hossain et al. also demonstrated that the concomitant use of steroids and LA injection was better than only LA injection in intensity and duration of pain relief. They proposed that the pain-relieving the impact of a locally injected steroid is largely depends on the local anti-inflammatory action and partially its central effect. Corticosteroid has also a strong irritant effect on peripheral nerve ending. Moreover, it awakes its act in pain modulation mechanism in the central nervous system inducing its analgesic action. What's more, corticosteroid owns characteristic softening and stretching impacts on the collagen, assists the growth of new fibrocytes, and ultimately decreases tissue tension (10). Therefore, in this study, the combination of LA and corticosteroid was chosen for TPI and a short-acting steroid was preferred because of possible side effects. The complications of TPI are muscle spasm, tenderness, and local infection sustaining for several hours to days $(9,10)$. There was no adverse effect in this study.

Today, KT is generally utilized as an assistance method in the rehabilitation of musculoskeletal disorders, prevention of injuries, treatment of fascia, muscles or joints dysfunctions, and lymphoedema. Moreover, it is demonstrated that KT could improve the ROM, diminishment of pain, decrease swelling, inflammation, and contusion, increase blood circulation, raise strength and muscle tone, and be employed in muscle spasms and prevention of cramping and speed up the healing of overused muscles $(5,12)$. KT could also be accustomed to deal pain within patients with MPS (5).

There are several hypotheses that indicate a possible analgesic effect of KT. One of these might be associated with the reduced subcutaneous nociceptor pressure in the skin through lifting the skin with the application of KT. An additional hypothesis is the gate control theory. The cutaneous stretch stimulation initiated by KT could affect nociceptive stimuli achieving the central nervous system and prevent the pain (13). Moreover, KT enhances blood and lymphatic fluid circulation under the taped area by a lifting effect that forms a wider area between the skin and the muscle. According to the theory of the action of KT on fascial tissues, the transmission of the relative tension created by the KT band to the appropriate receptors reveals the muscle response due to the direct connection between the fascia and the muscles. These might influence muscle functions and lead to the improvement in pain and $\operatorname{ROM}(14,15)$. It is believed that the pressure and stretching impact of KT on the skin stimulates cutaneous mechanoreceptors which transmit information about joint position and movement. In this way, it can increase proprioception (16).

The application techniques of KT contain inhibition, facilitation, field correction, fascia correction, functional correction, and mechanic correction techniques. The practitioner of KT must decide which muscle group should be treated with which type of technique. Furthermore, the proper technique should be performed after full examination of the affected muscle. In practice, the inhibition technique used for muscle dysfunction induced by microtrauma or tension is generally preferred (5). In this study, the field correction technique was performed to improve the circulation of tissue.

Gonzales-Iglesias et al. investigated the effect of KT application on whiplash injury and demonstrated improvements in terms of pain level (17). Hernandez et al. compared the efficacy of cervical manipulation and KT application in patients with mechanical neck pain. They found results similar to those of Gonzalez-Iglesias et al. (18). Karatas et al. examinated the efficacy of KT application on mechanical neck pain. They showed that patients treated with KT exhibited improvements in terms of pain (19). Ozturk et al. determined the short- and mid-term effects of KT on the trapezius muscle in individuals with MPS. They compared KT with sham KT application and found improvements in terms of pain level after KT application (20). Ay et al. compared the effects of KT and sham taping with 2 weeks follow-up and demonstrated that KT is successful for the improvement of findings including pain, pressure pain threshold, cervical range of motion, and neck disability (21). Considering these studies, it is thought that the combination of TPI and KT, which act at different points, may increase the duration of symptomatic effectivity in MPS. Ata et al. evaluated the efficacy of KT with that of local anesthetic injection alone on the degree of pain and quality of life in MPS and indicated that KT may be useful to increase the efficacy of lidocaine injection in MPS (22). The results of the study were in accordance with this study. This can be explained by an additive synergic effect of KT. 
When MTrP injection is used as the primary therapy, patients are at risk for becoming dependent on this treatment for pain relief because of the limited role of this treatment in the long-term management of MPS (23). Therefore, it has seemed that TPI plus KT on the trapezius muscle in the treatment of MPS may contribute to intermitting the progression of chronic process and prohibiting recurrence and blocking a vicious cycle of pain.

\section{Study Limitations}

Some limitations of the present study include sample size and the absences of the KT group, placebo group, longterm consequences, and using inhibition technique via KT. Further studies are needed to design with a placebo group and inhibition technique via KT to clarify the efficacy of this combination in the treatment of MPS.

\section{REFERENCES}

1. Simons D, Travell J, Simons L (editors). Travell and Simons' myofascial pain and dysfunction: the trigger point manual. 2nd ed. Baltimore: Williams \& Wilkins 1999:pp 94-173.

2. Sarrafzadeh J, Ahmadi A, Yassin M. The effects of pressure release, phonophoresis of hydrocortisone, and ultrasound on upper trapezius latent myofascial trigger point. Arch Phys Med Rehabil 2012;93(1):72-7.

3. Auleciems LM. Myofascial pain syndrome: a multidisciplinary approach. Nurse Pract 1995;20:18-28.

4. Han SC, Harrison P. Myofascial pain syndrome and trigger-point management. Reg Anesth 1997;22:89-101.

5. Alotaibi M, Ayoub A, King T, Uddin S. The Effect of Kinesio Taping in reducing Myofascial Pain Syndrome on the Upper Trapezius Muscle: A Systematic Review and Meta-Analysis. Eur Sci J 2018;14:336-50.

6. Alvarez DJ, Rockwell PG. Trigger points: diagnosis and management. Am Fam Physician 2002;65:653-60.

7. Tompson JM. The diagnosis and treatment of muscle pain. In: Physical Medicine \& Rehabilitation. Braddom RL., WB Saunders Comp, Philadelphia, 1997:pp 893-914.

8. Affaitati G, Fabrizio A, Savini A, et al. A randomized, controlled study comparing a lidocaine patch, a placebo patch, and anesthetic injection for treatment of trigger points in patients with myofascial pain syndrome: evaluation of pain and somatic pain thresholds. Clin Ther 2009;31:705-20.

9. Benzon HT, Katz JA, Benzon HA, Iqbal MS. Piriformis syndrome. Anatomic considerations, a new injection technique, and a review of the literature. Anesthesiology 2003;98:1442-8.

10. Hossain MHMD, Choudhury MRA, Mojumder MMA. A comparative study of treatment of backache between conventional method and trigger point injections (TPI). JAFMC Bangladesh 2009;5:37-40.

\section{CONCLUSIONS}

The complex pathology with underlying peripheral and central neural mechanisms of MPS might conduce to the difficulties within the treatment of MPS, especially within the chronic period. Furthermore, the presence of TrP related symptoms in some patients indicates that the treatment may require more than a single approach of injections. The combined therapy appears to generate a more influential outcome for the long run than monotherapy in alleviating pain and reforming functional amelioration in the management of MPS. The study meets the ethical standards of the journal (24).

\section{CONFLICT OF INTERESTS}

The author declares that she has no conflict of interests.

11. Sonne M, Kjeld C, Hansen SV, Jensen EM. Injection of steroids and local anaesthetics as therapy for low-back pain. Scand J Rheumatol 1985;14:343-5.

12. Kase K, Wallis J, Kase T. Clinical Therapeutic Applications of the Kinesio Taping Method, 2nd Edition, Kinesio Taping Association, Dallas, 2003.

13. Gusella A, Bettuolo M, Contiero F, Volpe G. Kinesiologic taping and muscular activity: a myofascial hypothesis and a randomised, blinded trial on healthy individuals. J Bodyw Mov Ther 2014;18:405-11.

14. Gómez-Soriano J, Abián-Vicén J, Aparicio-García C, et al. The effects of Kinesio taping on muscle tone in healthy subjects: a double-blind, placebo-controlled crossover trial. Man Ther 2014;19(2):131-6.

15. Yoshida A, Kahanov L. The effect of kinesio taping on lower trunk range of motions. Res Sports Med 2007;15:103-12.

16. Kase K: KT1: Fundimental concepts of the kinesiotaping method. KT2: Advanced concepts and corrective techniques of the kinesiotaping method. KT certificate program, Turkey, 2011.

17. González-Iglesias J, Fernández-de-Las-Peñas C, Cleland JA, Huijbregts P, Del Rosario Gutiérrez-Vega M. Short-term effects of cervical kinesio taping on pain and cervical range of motion in patients with acute whiplash injury: a randomized clinical trial. J Orthop Sports Phys Ther 2009;39:515-21.

18. Saavedra-Hernández M, Arroyo-Morales M, Cantarero-Villanueva I, et al. Short-term effects of spinal thrust joint manipulation in patients with chronic neck pain: a randomized clinical trial. Clin Rehabil 2013; 27: 504-12.

19. Karatas N, Bicici S, Baltaci G, Caner H. The effect of Kinesiotape application on functional performance in surgeons who have musculo-skeletal pain after performing surgery. Turk Neurosurg 2012;22:83-9.

20. Ozturk G, Kulcu Geler D, Mesci N, Silte AD, Aydog E. Efficacy of kinesio tape application on pain and muscle strength in 
patients with myofascial pain syndrome: a placebo-controlled trial. J Phys Ther Sci 2016;28:1074-79.

21. Ay S, Konak HE, Evick D, Kibar S. The effectiveness of Kinesio Taping on eain and disability in cervical myofascial pain syndrome. Rev Bras Reumatol 2017;57:93-9.

22. Ata E, Kosem M, Adiguzel E. Does kinesiotaping increase the efficacy of lidocaine injection in myofascial pain syndrome treatment? A randomized controlled study. J Back Musculoskelet Rehabil 2019;32: 471-7.
23. Lim EC, Tay MG. Kinesio taping in musculoskeletal pain and disability that lasts for more than 4 weeks: is it time to peel off the tape and throw it out with the sweat? A systematic review with meta-analysis focused on pain and also methods of tape application. Br J of Sports Med 2015;49:1558-66.

24. Padulo J, Oliva F, Frizziero A, Maffulli N. Muscles, Ligaments and Tendons Journal - Basic principles and recommendations in clinical and field Science Research: 2018 update. Muscles Ligaments Tendons J 2018;8(3):305-7. 